\title{
Dynamics of Malaria Epidemiology with Related Health Behavior of Urban Slum Residents: An Experience from Eastern India.
}

\author{
Subhrajyoti Naskar ${ }^{1}$, Shubhadeep Paul ${ }^{2}$, Anindya Mukherjee ${ }^{3}$, Amitava \\ Chatterjee ${ }^{4}$, Manidipa Roy ${ }^{5}$, Samir Dasgupta ${ }^{6}$ \\ ${ }^{1,2}$ (Assistant Professor, Department of Community Medicine, Malda Medical College, West Bengal, India) \\ ${ }^{3}$ (Assistant Professor, Department of Community Medicine, Medical College Kolkata, West Bengal, India) \\ ${ }^{4}$ (Assistant Professor, Department of Community Medicine, R.G.Kar Medical College, West Bengal, India) \\ ${ }^{5}$ (Professor, Department of Community Medicine, Behrampore Medical College, West Bengal, India) \\ ${ }^{6}$ (Professor, Department of Community Medicine, Burdwan Medical College, West Bengal, India)
}

\begin{abstract}
Background: Urban poor in India are highly vulnerable to malaria due to poor sanitary conditions, awareness and climate change. Methodology: an observational, descriptive study was carried out at ward 37 under Borough V of K.M.C. for one year. Records regarding malariometric indices in last 4 years were collected. Study population ( $n=342)$ were slide positive cases of malaria reporting in the malaria clinic. Data on socio demographic profile, environment, housing status, knowledge and practice regarding different aspects of malaria were collected. Quantitative assessment of knowledge and practice was done. Chi-square test and Pearson's correlation coefficient was computed. Results: All the malariometric indices increased gradually over the years (2006-09). There existed a seasonal trend in transmission of malaria. Male gender, nuclear family, higher education and higher socio-economic status were statistically significantly associated with both the higher knowledge and practice score. Conclusions and recommendations: socio-demographic factors are associated with knowledge and practice of malaria prevention. Malaria control must be based on disease epidemiology with emphasis on improvement of knowledge and practice of appropriate preventive measures.
\end{abstract}

Key Words: Malaria, malaria epidemiology, malariometric indices, practice

\section{Introduction:}

Malaria is one of the most important public health problems. ${ }^{1}$ It is the fourth leading cause of death of children under the age of five years in developing countries. The Population at risk is nearly 3.3 billion that is the half of the world population. ${ }^{2}$ The financial burden to tackle malaria was 6.2 billion US dollars in $2010 .{ }^{3}$ Malaria is a major public health concern in India. Climate change is increasing the population's vulnerability. One of the most vulnerable segments is the urban poor. ${ }^{2}$ Rapid urbanization, construction activities, unplanned town growth, poor sanitation, water storage practices, inadequate health infrastructure and awareness regarding malaria knowhow along with growing incidences of drug resistance making the situation worse. In Kolkata, a total of 56337 slide positive cases of malaria were found, with 6 deaths in the year $2008{ }^{4-7}$ Planning of integrated malaria control interventions must be based on local analysis of the epidemiological pattern of malaria. This analysis should also include community knowledge of malaria, practice of preventive measures, treatment seeking behaviors and associated socio-cultural factors that determine the changing trend of malaria transmission. ${ }^{8,9}$ Present study was attempted to assess the trends in the epidemiological parameters of malaria in the study area for last 4 years with seasonal variation in respect to number of cases and parasite species. We also studied socio-demographic characteristics, environmental conditions, knowledge and practice of respondents regarding malaria.

\section{Materials And Methods:}

An observational, descriptive epidemiological study comprising of record analysis, cross sectional clinic based data collection was carried out at ward 37 under Borough V of Kolkata Municipal Corporation (K.M.C.) for a period of one year [1st June 2009- $31^{\text {st }}$ May 2010]. All the records of last 4 years regarding malariometric indices in the study area were collected from malaria clinic of K.M.C. Study population was selected by purposive sampling, where slide positive cases of malaria reporting in the malaria clinic on the two predefined days in a week were considered. Ethical clearance was taken from the appropriate authority and informed consents were obtained from all respondents.

Final obtained sample size was 342. Data on socio demographic profile, environmental status, knowledge and practice regarding different aspects of malaria were collected from the respondents. For a case of less than 15 years the respondent was the accompanying adult. Duplication of responses was avoided (sample 
size was 328 in response to knowledge and practice related domain). Comparison of malaria cases and the epidemiological parameters was done with seasonal and species variation of cases for last 4 years (2006-09).

A scoring system was developed for quantitative assessment of knowledge regarding malaria and its prevention and the practice of these preventive measures. For each correct answer for knowledge questions 2 marks were awarded and each incorrect response entailed 0 mark; similarly in practice questions 'always' response got 2 marks, 'sometimes' got 1 mark and 'never' got 0 marks. Maximum and minimum possible score for both knowledge and practice questions were 18 and 0 respectively. Respondents were divided into two groups, those getting $\geq 50 \%$ of maximum obtainable score and others getting $<50 \%$ of maximum obtainable score. Socio demographic factors were cross tabulated and chi-square test was applied for test of significance. Pearson's correlation coefficient was also computed. Data were compiled and tabulated in MS Excel 2007 software and was analyzed with SPSS v16.0 software.

\section{Results:}

Recordanalysis: There existed a seasonal trend in the occurrence of P.vivax cases in the last four years (2006-2009). More or less P.vivax cases started to rise from spring (March -April), reached its peak in monsoon season (August-September), remained high till month of November and then declined in winter (December). P.falciparum malaria cases started to rise from monsoon season (August-September) remained high till month of November and then declined in winter season (December). The overall trend of malaria is depicted in figure 1.

Various malariometric indices over 2006 to 2009 are as follows: P falciparum cases were $7.12 \%$ in 2006 came down to $5.57 \%$ in 2007, increased to $21.07 \%$ in 2008 and remained at $19.1 \%$ in 2009 . The annual parasite incidence (API) decreased from 28.88 in 2006 to 18.98 in 2007, gradually increased to 21.79 in 2008 and 26.55 in 2009. Annual falciparum incidence was 2.06 in 2006, it decreased to 1.06 in 2007, then it increased sharply to 4.59 in 2008 and 5.1 in 2009. Annual blood examination rate (ABER) decreased from $12.79 \%$ in 2006 to $8.26 \%$ in 2007 and increased to $10.94 \%$ in 2008 and remained consistent in 2009. The slide positivity rate (SPR) was almost identical in 2006 and 2007 (22.58\% and 22.98\% respectively). After decreasing in 2008 (19.92\%), it again increased to $24.24 \%$ in 2009 .

Cross sectional, clinic based study: Most of the study population (25.73\%) belonged to the age group of 5-14 years with majority of study population $(48.25 \%)$ were $\leq 24$ years of age. The mean age of study population was 30.84 years with standard deviation 18.35 years. Most of them $(63.7 \%)$ were males and 55\% were Hindus. Among the study population $17.8 \%$ were illiterate, $2.9 \%$ were graduate and above and most of them $(36 \%)$ studied between Class V-class VIII. Majority (54.7\%) belonged to nuclear family. Majority belonged to lower middle $(48.00 \%)$ and poor $(41.80 \%)$ class with $3.8 \%$ was below poverty line. (Table-1)

Maximum correct response was obtained (86.28\%) regarding 'vector of malaria' and minimum (25.91\%) regarding 'Complication of malaria'. Majority (64.94\%) of the study population got $\geq 50 \%$ maximum possible score regarding knowledge of malaria. (Table-2)

The response of "always" was obtained maximally for the practice regarding "keeping stored water covered' (52.44\%) and minimally for 'wearing long sleeve cloth at night' or 'cleaning stagnant water in and around the house.' Among the respondents $40.54 \%$ got $\geq 50 \%$ of maximum possible practice score regarding malaria. (Table-3)

Mean knowledge score was higher than mean practice score but both showed high correlation. Male gender, nuclear family, higher education and higher socio-economic status of the study respondents were statistically significantly associated with both the higher knowledge as well as practice score. Religion was significantly associated only with knowledge score.(Table 4).

\section{Discussion:}

Haphazard and unplanned growth of towns has resulted in creation of "urban slums" with poor drainage system, water logging and indoor water storage in open containers responsible for malariogenic conditions. ${ }^{10}$ The local analysis on epidemiology, community knowledge, practice of preventing measures, treatments seeking behavior, associated socio-cultural factors are essential for planning of integrated malaria control interventions. Local temperature, humidity and rainfall have significant effect on sustaining breeding places and increasing life span of mosquitoes. ${ }^{11,12}$

The P.vivax cases reached its peak in monsoon (July onwards) and then declined in winter (December) whereas there was a delay in rising of P. falciparum cases (August-September) and then declined in December. The delayed transmission of P.falciparum may be due to late appearance of gametocytes and longer extrinsic cycle. Malaria transmission peaked from June-November in Assam, July-October in Chennai and August-September in Delhi. ${ }^{13}$

We found that maximum blood slides were examined in 2006 and minimum in 2007 during 20062009. The slide positivity rate was increased to $24.24 \%$ in the year 2009. Annual parasite incidence was 26.55 in 
the year 2009. Annual blood examination rate was $10.95 \%$ in the year 2009. Annual falciparum incidence was 5.1 in the year 2009. P.falciparum \% was 19.10 in 2009.

In West Bengal P.falciparum \% was $26.9 \%$ in 2006, it decreased to $25 \%$ in 2007 and again increased in $2008(27.3 \%)$. In 2006 API was 1.9; in 2007 it decreased to 1.1 and remained same in 2008. In 2006 ABER was $6.2 \%$, in 2007 it decreased to $5.6 \%$ and remained more or less same in 2008 (5.4\%). SPR was $3 \%$ in 2006, it decreased to $1.9 \%$ in 2007 and remained at $2 \%$ in $2008 .^{14}$

In Kolkata P.falciparum \% was $5.48 \%$ in 2007 and it shoot up to $30.27 \%$ in 2008 . API was 2.85 in 2007 and increased to 10.69 in 2008. ABER was $2.12 \%$ in 2007 and increased to $5.84 \%$ in 2008. SPR was $13.45 \%$ in 2007 and it increased to $27.24 \%$ in $2008 .{ }^{14}$

In the present study $48.25 \%$ of the population was $\leq 24$ years of age. Ali Karimi-Zarchi et al ${ }^{15}$ showed that mean age of malaria patients was 22.5 years. Younger age groups were mostly affected by malaria like 10-19 years at Thai-Cambodia border (November 2000); ${ }^{10} 0-9$ years in Orissa mines (1989); 0-2 years in Koraput district in Orissa(1989). Reverse was reported with increased incidence among older age group after implementation of eradication programs by Pattanayak et al(1970s); ${ }^{17}$ during 1984-85 various state wise surveys in India and in Nepal, Sri Lanka, Thailand and Myanmar during 90s .

In present study marked preponderance of male cases (63.7\%) were found corroborating with studies conducted by Ali Karimi-Zarchi et al , ${ }^{15}$ a study in Ghana, a study reported by Nicastri et al ${ }^{18}$ or a study at Zurich university (2010). ${ }^{19}$ The cause may be men producing more carbon-di-oxide and tend to sweat more attracting mosquitoes. The hormones testosterone and estrogen may influence immunological response to the parasite in post-pubertal period. ${ }^{19}$ Contradictory observations in Haiti (1991-92) showed that females were at significantly higher risk of Falciparum malaria infection $(4.91 \%$ vs. $2.78 \%) .{ }^{20}$ Malaria mortality rate was 1.5 times higher among females in Gujrat. Beljaev et al during 1981-83, found no evidence of sex difference with high incidence of P.falciparum. ${ }^{21}$

Literacy was identified as one of the most important factors associated with knowledge regarding prevention of malaria. ${ }^{22,23}$ Among the malaria patients $24.8 \%$ were illiterate/just literate and only $2.9 \%$ were graduates in the present study. Similar findings were noted among mobile Cambodians in Aranyaprathet at the Thai-Cambodia border (November 2000). ${ }^{16}$

In present study malaria incidence rate was considerably higher among the lower socio-economic groups and corroborated with the findings of many workers. It may be due to creating of the preconditions, malnutrition, poor housing, increased outdoor activities after dark and deficient personal hygiene. ${ }^{22}$

In present study majority of houses had problem of overcrowding, inadequate light and ventilation as like any other slums. Residents stored water in open containers for longer durations. The overall housing and environmental conditions favored malaria occurrence. ${ }^{22}$ Water storage practices were responsible for Anopheles stephensi in south Kolkata. Yazoume Ye et al in Israel (2006) and Konradsen et al in Sri Lanka showed that housing characteristics were significantly associated with malaria transmission.

In present study $76.22 \%$ knew that infected mosquito bite transmitted the disease while in other studies the proportion varied from 4.36\% (Maharashtra), 66\% in Zimbabwe, 98\% in Sri Lanka, 48\% (Legesse et al) ${ }^{22}$ and $90 \%$ (Njama et al). ${ }^{23}$ In present study $63.41 \%$ of the respondents identified breeding sites of mosquito corroborating with a study in Tanzania . Feeding time of malaria mosquito was identified correctly by $41.46 \%$ of respondents lower than $95 \%$ obtained by Legesse et al. ${ }^{22}$ Common symptoms of malaria were identified correctly by $71.34 \%$ of respondents compared to $85 \%$ in Ethiopia and $70 \%$ reported by Sultana et al. ${ }^{112,25}$ In present study $76.52 \%$ respondents correctly identified preventive measures as compared to $52-58 \%$ reported by Legesse et al ${ }^{22}$ and $56 \%$ reported by Sultana et al. ${ }^{24}$

Regular use of mosquito nets are associated with decline in malaria incidence. In Gambia parasitemia was present in $53 \%$ of people not using bed nets compared to $31 \%$ of people who used well maintained nets. In the present study $14.65 \%$ respondents never used mosquito net. The causes of non usage were lack of adequate floor space, lack of sufficient income or feeling hot under a net. Regular use of mosquito net was reported by $90.2 \%$ (Thanabouasy et al), ${ }^{25} 40 \%$ (Sultana et al), ${ }^{24} 25 \%$ (Njama et al). ${ }^{23}$ In the present study $46.03 \%$ of respondents slept outdoor always/sometimes making them vulnerable to malaria. Sleeping indoors was associated with reduced malaria incidence in literature. ${ }^{24,25}$ In the present study $1.5 \%$ respondents used repellent coils at night regularly. Sultana $\mathrm{et}^{\mathrm{al}^{24}}$ showed that $20 \%$ of respondents were using mosquito repellents regularly while it was $9.2 \%$ as per Thanabouasy et al. ${ }^{25}$ In present study $35.06 \%$ respondents never allowed health workers to use anti-mosquito measures around their house.

In the present study mean knowledge score (10.73) was higher than mean practice score (7.29). Knowledge and practice score showed high correlation. Males obtained significantly higher knowledge and practice scores than females (except for caregiver group). Muslim respondents had significantly higher knowledge scores than Hindus. Residents of nuclear families scored significantly higher in both knowledge and practice aspects. Knowledge and practice scores were significantly higher with higher education and socioeconomic status. 
In Thailand malaria incidence declined with higher knowledge and practice score. Scores increased significantly with rising literacy levels, the practice scores were lesser than knowledge scores but positively correlated. Pinikahana et al (Sri Lanka 1990) showed that insufficient knowledge played significant role in malaria transmission. Thanabouasy et $\mathrm{al}^{25}(2009)$ also found that education, occupation, monthly family income were significantly associated with knowledge and practice score on malaria prevention.

\section{Conclusion:}

Despite the limitations like consideration of only a single slum due to resource constraint along with possibility of recall bias and cross sectional recording of knowledge and practice the present study came up with many important findings. All the malariometric indices increased gradually over the years (2006-09). There existed a seasonal trend in transmission of malaria. Majority of study population $(64.94 \%)$ got $\geq 50 \%$ maximum possible knowledge score but only $40.54 \%$ got $\geq 50 \%$ of maximum possible practice score. Male gender, nuclear family, higher education and higher socio-economic status were statistically significantly associated with both the higher knowledge and practice score. So, malaria control must be based on disease epidemiology with emphasis on improvement of knowledge and practice of appropriate preventive measures. Socio-economic status, housing, water storage, sanitation, waste disposal facilities should be improved. The people should cooperate with municipal health workers. Mosquito nets/repellents may be provided to the poor free of cost.

\section{References:}

[1] Health Bulletin for Asha on Prevention and Control of Vector Borne Diseases (2007): MALARIA Bulletin; 4. Available at http://nvbdcp.gov.in/health-bulletin-asha.html,nvbdcp.gov.in/Doc/HB4\%20April\%202007.pdf. (Accessed on 20/ 11/2009).

[2] Roll Back Malaria Key Malaria Facts: Available at http:// http://rbm.who.int/ keyfacts.html (accessed on 22/07/2009).

[3] World Malaria Report: 2009; Available at http://who.int/entity/ malaria/ publications//mal2009_india_0023.pdf (accessed on 22/07/2009).

[4] Malaria A Growing Concern In India Cities: Available at http:// info change india.org/200904287731/Health/Analysis/Malaria-agrowing-concern-in-India-cities.html (accessed on 21/02/10).

[5] Malaria Situation In India: Available at http://nvbdep.gov.in/ (accessed on 01/08/2009).

[6] Urban Malaria Scheme (UMS) : Available at http://nvbdcp.gov.in/ (accessed on 02/08/2009).

[7] Health on the March 2007-08: State Bureau of Health Intelligence, Directorate of Health Services, Govt. of West Bengal; p. $135-141$.

[8] Sharma Vinod P. Battling the Malaria Iceberg with Chloroquine in India. India Malaria Journal. 2007; 6(1):105. Available at http:// www. Malaria journal.com/content/6/1/105 (accessed on 04/08/2009).

[9] Korenromp EL. Malaria Incidence Estimates At Country Level For The Year 2004, RBM Monitoring and Evaluation Reference Group and MERG, WHO, RBM Dr.aft Report, March11,2005.Available at http://www.who.int/ malaria/docs/incidence estimations2.pdf (accessed on 04/08/2009).

[10] Urban Slums Reports: The case of Kolkata, India: Available at http://www.ucl.ac.uk/dpuprojects/Global_Report/pdfs/Kolkata.pdf(accessed on 12/09/2009)

[11] Expert committee on malaria; Malaria Action Programme Based on Expert Committee Report-1995. Govt. of India, NMEP, Ministry of Health and Family Welfare.1995: 1-32.

[12] Sharma R S, Sharma G K, Dhillon G P S. Malaria Paradigms and their Transmission Dynamics. In: Epidemiology and Control of Malaria in India 1996. Govt. of India, NMEP, Ministry of Health and Family Welfare.1996; 129-200.

[13] Kondrashin A V, Rashid K M. Urban Malaria; Epidemiological consideration for Planning Malaria Control in South-East Asia. WHO/SEARO Technical Publication.1987. 17: 331-347.

[14] Annual District wise Epidemiological Report of Malaria, West Bengal: Available athttp://www.wbhealth.gov.in/Statistics\%20_Html/2008_2009/9/9_13.htm (accessed on 04/04/2010).

[15] Karimi-Zarchi A A, Mahmoodzadeh A, Vatani A. A Survey On Malaria And Some Related Factors In South East Of Caspian Sea.Pak J Med Sci .2006; 22.(4):489-492.

[16] Kitvatanachai S et al. A Survey On Malaria In Mobile Cambodians In Aranyaprathet, Sa Kaeo Province,Thailand. Southeast Asian J Trop Med Public Health. 2003; 34. (1):48-53.

[17] Pattanayak S, Roy R G, Ghosh R B. Reappearing Malaria In Different Age-Groups In Karnataka State. J. comm. Dis.1978; 10.(1): 21-26.

[18] Nicastri E et al. Plasmodium Falciparum Multiple Infections, Disease Severity And Host Characteristics In Malaria Affected Travellers Returning From Africa;Travel Medicine and infectious disease. 2008; 6.(4) : 205-209.

[19] Men-More-Prone-To-Malaria (2010):Bhayana N.Hindustan Times; available at http://www.hindustantimes.com/Men-more-prone-tomalaria-think-city-researchers/Article1-580631.aspx (accessed on 03/05/10).

[20] Monte Bauden P, Douglas Slaten D, John Malone D. Malaria In A Displaced Haitian Population. Trans. R. Soc. Trop. Med. Hyg. 1995;89:600- 603.

[21] Beljaev A E, Broht J A, Sharma G K, Samantaray K C. Studies on the Detection of Malaria at Primary Health Centres. Part III. Parasitological Profile of Population Surveyed for Malaria through Passive Case Detection. Indian J. Malariol.1987; 24.(4): 97-106.

[22] Legesse Y et al. Knowledge, Attitude and Practice about Malaria Transmission and Its Preventive Measures among Households in Urban Areas of Assosa Zone, Western Ethiopia. Ethiop.J.Health Dev. 2007;21.(2):157-165.

[23] Njama D et al. Urban Malaria: Primary Caregivers' Knowledge, Attitudes, Practices And Predictors Of Malaria Incidence In A Cohort Of Ugandan Children. Trop Med Int Health.2003; 8.(8):685-92.

[24] Sultana A et al.Malaria, Knowledge, Attitude \& Practice in a Semi-Urban Population of Rawalpindi. Professional Med J. Oct - Dec $2001 ; 8 .(4): 433-8$.

[25] Thanabouasy $\mathrm{C}$ et al. Assessment of Knowledge, Attitude, And Practice Regarding Malaria Prevention Towards Population In Paksong District, Champasack Province, Lao Pdr. J Health Res. 2009; 23. (suppl) : 11-15. 


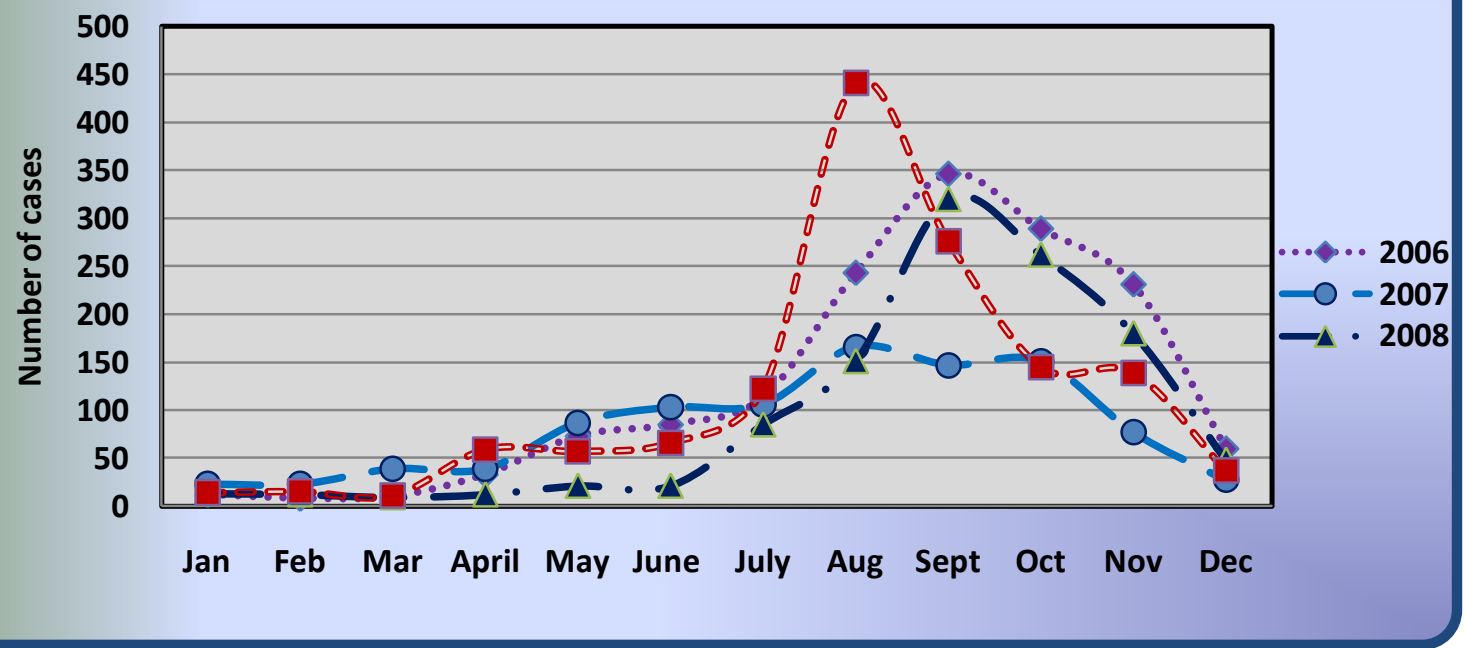

Fig: 1 Line diagram showing month wise distribution of overall malaria cases during 2006 to 2009.

Table 1: Socio-demographic profile of the study population $(n=342)$

\begin{tabular}{|cccc|}
\hline \multicolumn{2}{c}{ Socio-demographic variables } & Frequency & Percentage \\
\hline Age group (years) & $5-14$ & 88 & 25.73 \\
& $15-24$ & 77 & 22.52 \\
& $25-34$ & 44 & 12.87 \\
& $35-44$ & 41 & 11.99 \\
& $45-54$ & 39 & 11.40 \\
& $\geq 55$ & 53 & 15.49 \\
\hline Sex & Male & 218 & 63.7 \\
& Female & 124 & 36.3 \\
\hline Religion & Hindu & 188 & 55.0 \\
& Muslim & 154 & 45.0 \\
\hline Literacy status & Illiterate & 61 & 17.8 \\
& Just literate & 24 & 7.0 \\
& Up to class IV & 86 & 25.1 \\
& Class V-class VIII & 123 & 36.0 \\
& Class IX-class X & 22 & 6.4 \\
& Class XI-class XII & 16 & 4.7 \\
& Graduate and above & 10 & 2.9 \\
\hline Type of family & Nuclear & 187 & 54.7 \\
& Joint & 155 & 45.3 \\
\hline Socio economic status & High [5000-9999] & 5 & 1.5 \\
[per capita monthly & Upper middle [3000-4999] & 17 & 5.0 \\
income in Rs] & Lower middle [1500-2999] & 164 & 48.0 \\
& Poor [500-1499] & 143 & 41.8 \\
& Below poverty line[<500] & 13 & 3.80 \\
\hline
\end{tabular}


Table 2: Distribution of study population according to response to questions on knowledge domain regarding malaria $(n=328)$

\begin{tabular}{|ccc|}
\hline Questions & \multicolumn{2}{c|}{ Response } \\
& Correct frequency $(\%)$ & Incorrect frequency $(\%)$ \\
\hline Vector of Malaria & $283(86.28)$ & $45(13.72)$ \\
Transmission of malaria & $250(76.22)$ & $78(23.78)$ \\
Breeding site of mosquito & $208(63.41)$ & $120(36.59)$ \\
Feeding time of malaria mosquito & $136(41.46)$ & $192(58.54)$ \\
Common symptoms of malaria & $234(71.34)$ & $94(28.66)$ \\
Diagnosis of malaria & $104(31.70)$ & $224(68.30)$ \\
Prevention of malaria & $251(76.52)$ & $77(23.48)$ \\
Curability of malaria & $209(63.72)$ & $119(36.28)$ \\
Complication of malaria & $85(25.91)$ & $243(74.09)$ \\
& & \\
\hline
\end{tabular}

Table 3: Distribution of study population according to response to questions on psychomotor/practice domain regarding malaria $(n=328)$

\begin{tabular}{|c|c|c|c|}
\hline \multirow[t]{2}{*}{ Questions } & \multicolumn{3}{|c|}{ Response } \\
\hline & $\begin{array}{c}\text { Always } \\
\text { Frequency }(\%)\end{array}$ & $\begin{array}{l}\text { Sometimes } \\
\text { Frequency }(\%)\end{array}$ & $\begin{array}{c}\text { Never } \\
\text { Frequency }(\%)\end{array}$ \\
\hline Sleep in mosquito net & $127(38.71)$ & $153(46.64)$ & $48(14.65)$ \\
\hline Sleep outdoors & $23(7.01)$ & $128(39.02)$ & $177(53.97)$ \\
\hline Keeps stored water covered & $172(52.44)$ & $76(23.17)$ & $80(24.39)$ \\
\hline Use repellent coil at night time & $5(1.50)$ & $169(51.50)$ & $154(47.00)$ \\
\hline $\begin{array}{l}\text { Allow health workers use anti- } \\
\text { mosquito measures around your } \\
\text { house }\end{array}$ & $40(12.20)$ & $173(52.74)$ & $115(35.06)$ \\
\hline $\begin{array}{l}\text { Wear long-sleeve cloth during } \\
\text { night time }\end{array}$ & $0(0)$ & $115(35.06)$ & $213(64.94)$ \\
\hline $\begin{array}{l}\text { Clean the stagnant water in and } \\
\text { around your house }\end{array}$ & $0(0)$ & $200(60.98)$ & $128(39.02)$ \\
\hline Clear the dark corner in your house & $16(4.88)$ & $254(77.44)$ & $58(17.68)$ \\
\hline Go to doctor when you get fever & $104(31.71)$ & $171(52.14)$ & $53(16.15)$ \\
\hline
\end{tabular}

Table 4: Correlation of knowledge and practice score; distribution of study population according to median score obtained; correlation of knowledge score and practice score obtained by study population with socio-demographic variables. $(n=328)$

\begin{tabular}{|c|c|c|c|c|}
\hline Indices & $\begin{array}{l}\text { Marks/score } \\
\text { obtained }\end{array}$ & $\begin{array}{l}\text { Frequency } \\
\text { (percentage) }\end{array}$ & Variables & $\begin{array}{c}\text { Pearson Chi-Square, } \\
\text { Df, p value }\end{array}$ \\
\hline \multirow{5}{*}{$\begin{array}{l}\text { Knowledge } \\
\text { score }\end{array}$} & $\geq 50 \%$ of & 213 & Sex & $85.888,1,<0.001$ \\
\hline & maximum possible & (64.94) & Religion & $23.575,1,<0.001$ \\
\hline & score & & Type of family & $7.563,1,0.004$ \\
\hline & $<50 \%$ of & 115 & Educational status & $180.165,3,<0.001$ \\
\hline & $\begin{array}{l}\text { maximum possible } \\
\text { score }\end{array}$ & (35.06) & Socio economic status & $41.163,2,<0.001$ \\
\hline \multirow{4}{*}{ Practice score } & $\geq 50 \%$ of & 133 & Sex & $41.817,1,<0.001$ \\
\hline & maximum & (40.54) & Religion & $2.661,1,0.102$ \\
\hline & obtainable score & & Type of family & $23.016,1,<0.001$ \\
\hline & $\begin{array}{c}<50 \% \text { of } \\
\text { maximum } \\
\text { obtainable score }\end{array}$ & $\begin{array}{c}195 \\
(59.45)\end{array}$ & $\begin{array}{l}\text { Educational status } \\
\text { Socio economic status }\end{array}$ & $\begin{array}{c}85.1859,3,<0.001 \\
39.756,2,<0.001\end{array}$ \\
\hline
\end{tabular}

